\title{
O ESTADO DEMOCRÁTICO DE DIREITO COMO LIMITADOR DO PODER POLÍTICO ATUAL E UMA NOVA CULTURA SOCIAL PARA PROMOÇÃO DO DESENVOLVIMENTO E DA SUSTENTABILIDADE
}

\author{
STATE DEMOCRATIC RIGHTS AS CURRENT POLITICAL POWER LIMIT \\ AND A NEW CULTURE FOR SOCIAL PROMOTION OF DEVELOPMENT AND \\ SUSTAINABILITY
}

${ }^{1}$ Cátia Rejane Liczbinski Sarreta

\section{RESUMO}

O estudo proposto refere-se à Democracia e o poder política considerando a implementação da sustentabilidade. Apresenta como base teórica o próprio princípio democrático, bem como a concretização dos direitos humanos e fundamentais. Analisa a possibilidade da re (construção) do Estado e do própria poder e cultura política e social por meio da democracia para a promoção do desenvolvimento e da sustentabilidade.Em um Estado Democrático o poder político adequado concretiza os direitos do cidadão. Um elemento fundamental que deve ser considerado é a educação para formação de atores sociais capazes da promoção das transformações das práticas dominantes e que , assumam papéis importantes na política e influenciam o Estado e a sociedade. O método utilizado é o dedutivo.

Palavras-chave: Cultura, Democracia, Poder politico

\begin{abstract}
The proposed study relates to the democracy and political power considering the implementation of sustainability. Presented as theoretical basis the democratic principle itself, as well as the realization of human and fundamental rights. Exploring the possibility of re (construction) of the state and own power and political and social culture of democracy through the promotion of development and sustainability. In a democratic state the appropriate political power embodies the rights of the citizen. A key element that should be considered is education for training social actors capable of promoting the transformation of dominant practices and that take important roles in politics and influence the state and society. The method used is deductive.
\end{abstract}

Keywords: Culture, Democracy, Political power

\footnotetext{
${ }^{1}$ Doutora em Ciências Sociais pela Universidade do Vale do Rio dos Sinos, UNISINOS, Rio Grande do Sul (Brasil). Professora em Direito Civil pela Fundação Getúlio Vargas - FGV, São Paulo (Brasil).

E-mail: catia_sarreta@hotmail.com
} 


\section{INTRODUÇÃO}

A cultura se faz presente no poder político, ao contrario do que muitos possam imaginar, tanto um quanto outro possuem grande influência no cotidiano da sociedade. $\mathrm{O}$ estudo se preocupa em mesmo com o futuro incerto da democracia, estabelecer orientações analisando o processo de democratização e suas influências transformadores no poder política e atual cultura aplicada e na sociedade, para a busca da sustentabilidade nas suas dimensões e ou concepções.

A cultura e o poder político possuem como elemento em comum a força que pode ser exercida através de vários métodos e não somente da força física, mas, a mais utilizada, é a dominação. A dominação é o elemento mais perceptível na conjectura do Estado Democrático atual, haja vista que o povo como um todo na maior parte das vezes não possui o conhecimento necessário para identificar a dominação exercida pelos detentores do poder político. Neste viés de dominação versus subordinação mister se fará analisar os legitimados ao exercício do poder e o meio cultural político que esta inserida a sociedade bem como os problemas decorrentes destes.

Assim, sob esta ótica, o presente trabalho tem como finalidade principal compreender a Cultura que permeia o Poder Político no Estado Democrático de Direito, bem como compreender suas influências na sociedade tentando caminhar para uma democratização da Cultura do Poder Político. Além destes aspectos, caberá analisar a relação de representatividade e a Democracia. Afinal de contas, pode-se falar em um Estado Democrático de acordo com a regra da maioria? Como a cultura e o poder político estão relacionados? Há meios de transformação da cultura do poder político atual? De modo a responder essas e demais perguntas é que este estudo será realizado. Todavia, atualmente fala-se sobre democratização em vários âmbitos, tanto jurídico como sociológicos, mas tal pesquisa se limitará ao estudo da democracia participativa, visto que esta é o principal meio para a compreensão do tema.

Além dessas questões, importante salientar que o estudo propõe analisar e responder os questionamentos, com base nas percepções sociais. Por percepção pode-se entender que é a sensibilidade de entender e compreender o que está ocorrendo entorno dos indivíduos. Deste modo, um dos elementos mais importantes deste estudo é a percepção, visto que é sob sua ótica que este estudo foi elaborado, buscando compreender a realidade da cultura política que permeia a sociedade bem como analisar se existe a limitação dessas percepções do indivíduo pelo poder político. 
Com base nestes apontamentos, pode-se dizer que um dos questionamentos que embasa este trabalho é: Como a percepção pelos indivíduos pode mudar a realidade da cultura do poder político atual? Existe limitação para a percepção do indivíduo? Com base nas percepções, ou seja, de modo a compreender a situação da sociedade em termos de cultura política, se obterá respostas que se efetivadas podem transformar a atual realidade política brasileira.

Portanto, ressalta-se que as percepções partem de cada individuo, sendo que cada um ao compreender a realidade que está inserido, precisa contribuir para que se tornem agentes da transformação política, criando assim, novas percepções de cultura.

Para a realização do artigo utilizou-se o método dedutivo.

\section{NOÇÕES SOBRE DEMOCRACIA NO CONTEXTO DOS DIREITOS HUMANOS}

Desde os primórdios das civilizações existem debates a respeito das formas de Estado e formas de Governo. Parece até mesmo uma discussão sem rumo certo, visto que a sociedade está em constante transformação, evoluindo e também regredindo. Porém, no que tange à democracia pode-se afirmar que durante os séculos em que

[...] tem sido discutida, debatida, apoiada, atacada, ignorada, estabelecida, praticada, destruída e depois às vezes restabelecida, aparentemente não resultaram em concordância sobre algumas das questões fundamentais sobre a democracia (DAHL, 2001, p. 12).

O único ponto passível de consenso, ao falar em democracia, é considerá-la e caracterizá-la por um conjunto de regras (primárias ou fundamentais) que estabelecem quem está autorizado a tomar as decisões coletivas e com quais procedimentos (BOBBIO, 1997). Em relação ao conceito de democracia, já de antemão pode-se observar duas formas de análise: democracia direta (utilizada à priori) e democracia representativa (verificada atualmente). A democracia representativa está consubstanciada no direito ao voto, na figura das eleições para a escolha do representante da maioria. No entanto, observa-se que esta é o poder de decisão da maioria, mas a maioria não decide, ela meramente elege alguém que decida por ela. Pode-se afirmar que

O Estado em uma democracia representativa deve ser constituído politicamente e burocraticamente de modo que nem os partidos políticos se estatizem e nem a população despolitizada a administre com vistas ao desenvolvimento estritamente privado. Daí a importância de auto-gestão, ou 
seja, de um povo que participe das tomadas de decisões, sendo então, ator e autor das determinações e ações do Estado. Contudo, o que vai necessariamente harmonizar a disputa entre o poder e o interesse é o direito normativo, e isso ocorre no Estado por meio da constituição que o rege com regras bem definidas a partir das cláusulas pétreas. (RIBEIRO, 2011, p. 27)

Enquanto isso, a democracia direta consistia na reunião de cidadãos na praça ou em assembléia para a tomada de decisões. A palavra “'Democracia' vem do significado de poder do démos, o contrário é observado atualmente, pois o que se nota é o poder dos representantes do démos." (BOBBIO, 2000, p. 377). Todavia, há de se considerar que a “democracia' tem significados diferentes para povos diferentes em diferentes tempos e diferentes lugares" (DAHL, 2001, p. 13). Deste modo, a democracia pode ser definida como

[...] uma forma de governo e organização de um Estado na qual a tomada de decisões políticas é feita por mecanismos de participação direta - quando o cidadão expressa a sua vontade por meio do voto em um assunto particular ou indireta, quando elege representante e lhes dá poder para que tomem decisões em seu nome. É a institucionalização da liberdade, isto é, de um conjunto de princípios e praticas que protegem a liberdade humana. (MARX, 2007).

O conceito mais adequado de democracia não pode se limitar a um procedimento de decisão centrado somente em eleições e regra da maioria, pois a mesma precisa abarcar o argumento como elemento constitutivo, concretizando-se assim a democracia deliberativa que tenta "institucionalizar o discurso, tão amplamente quanto possível, como meio da tomada de decisão pública” (ALEXY, 2011).

Ao longo da história a democracia passou por diversas condições, favoráveis e desfavoráveis; por diversos lugares e momentos, sendo que em alguns deles ficou esquecida. No entanto, por volta de 500 a.C., parece ter ressurgido condições favoráveis para sua discussão em diversos locais. Logo, pressupõe-se que

[...] a democracia possa ser inventada e reinventada de maneira autônoma sempre que existirem as condições adequadas. [...] essas condições adequadas existiram em diferentes épocas e em lugares diferentes. Assim como uma terra que pode ser cultivada e a devida quantidade de chuva estimularam o desenvolvimento da agricultura, determinadas condições favoráveis, sempre apoiaram uma tendência para o desenvolvimento de um governo democrático (DAHL, 2001, p. 19).

Em tempos modernos, a democracia está e é umbilicalmente ligada aos ideais revolucionários de 1930, diante da Revolução Francesa: a igualdade, fraternidade e solidariedade. A partir de então, os jusnaturalistas partem de uma análise 
individualizada dos seres humanos, onde seus direitos pertencem a cada ser desde o início. Esses direitos são inerentes à condição humana e por isso são inalienáveis e invioláveis.

A democracia moderna tem como principal fundamento a Declaração Universal dos Direitos do Homem e do Cidadão, o que era desconhecido na democracia antiga. Esta nova percepção de democracia depende do reconhecimento de direitos fundamentais, pois

\footnotetext{
Em uma sociedade democrática, algumas questões decisivas devem ser tratadas como questões de princípios - morais ou políticos - e não como uma questão de poder político, de vontade majoritária. São elas as que envolvem direitos fundamentais das pessoas, e não escolhas gerais sobre como promover o bem-estar social (DWORKIN, 1985, p. 69-71).
}

Cumpre enfatizar que em uma concepção moderna, o poder esta nas mãos de cada um dos cidadãos e não na mão do povo, pois é o individuo de modo singular o detentor do poder e pode-se dizer que aí está todo o enredo da democracia. Na democracia todo poder é representativo, o que significa dizer que deve ser transparente e prestar contas à sociedade e, por isso, nenhum poder pode estar fora do controle social (SANTISO, 2004, p. 172-177).

Fala-se em soberania de cada um dos indivíduos, sendo que é cada um deles que detém o poder enquanto cidadãos, em relação à soberania de um povo, considerando que só se percebe a soberania do povo a partir da instituição do sufrágio universal (BOBBIO, 2000, p. 379). Destarte, compreende-se que a democracia foi constituída com o intuito e fundamento para que todos os indivíduos, ou melhor, todos os cidadãos pudessem opinar. Logo, apresenta-se a democracia como

[...] aquela forma de exercício da função governativa em que a vontade soberana do povo decide, direta ou indiretamente, todas as questões de governo, de tal sorte que o povo seja sempre o titular e o objeto, a saber, o sujeito ativo e o sujeito passivo do poder legítimo (BONAVIDES, 1993, p. 13).

A democracia pode ser considerada como um direito fundamental de quarta geração, tendo em vista a luta pela repolitização de sua legitimidade. Trata-se de indivíduos que possuem legitimidade para escolher representantes para o exercício do Poder. Esse processo de escolha se dá através da eleição, sendo adotado um sistema majoritário, ou seja, a decisão da maioria se sobrepõe sobre da minoria.

Observa-se que "no mundo todo, estão surgindo novos debates sobre como revitalizar e aprofundar a democracia [...] é crescente a preocupação com o 'déficit 
democrático' ou com a 'perda de vitalidade da democracia"” (GAVENTA, 2004, p. 7). Deste modo, este estudo pretende analisar a relação entre democracia e direitos humanos, com o intuito de investigar qual a influência das Cortes Internacionais, sobretudo da Corte Interamericana de Direitos Humanos, na democracia dos Estadospartes com ênfase no Brasil. Para tanto, torna-se primordial a análise quanto à efetivação da democracia no Estado Democrático de Direito.

\subsection{A relação entre Democracia e Direitos Humanos}

Conforme se observou, o Estado Democrático de Direito não conseguiu garantir de fato a democracia e ainda há grandes deficiências quanto à garantia dos direitos assegurados pela Constituição. Consequentemente, a preocupação social incorporada ao Estado não foi suficiente para oferecer solução ao problema da igualdade. Apresenta-se, portanto, a preocupação com a caracterização democrática do Estado, de tal forma que

se desenvolve um novo conceito, na tentativa do conjugar o ideal democrático ao Estado de Direito, não como uma aposição de conceitos, mas sob um conteúdo próprio onde estão presentes as conquistas democráticas, as garantias jurídicolegais e a preocupação social. Tudo constituindo um novo conjunto onde a preocupação básica é a transformação do status quo. (STRECK; MORAIS, 2001, p. 92).

Enquanto um Estado de Direito Formal é definido pelo sistema da separação dos poderes, sendo apenas uma condição necessária, mas não suficiente para a garantia dos direitos humanos, e um Estado Democrático de Direito respeita os direitos humanos como direitos fundamentais, mas decide sozinho sobre a violação dos direitos fundamentais da soberania democrática, sugere-se como modelo de autoligação um Estado Democrático Constitucional, com justiça constitucional (ALEXY, 1998, p. 244264).

A supremacia constitucional atribui à Constituição função de ser a norma conformadora da ordem jurídica. De forma que a produção normativa decorre da própria Constituição e é nesta, consequentemente, que se encontra o fundamento de validade, tanto formal como substancial, das normas do Estado. Destarte, no exercício da atividade jurisdicional, a subordinação à legalidade existe somente em função de leis que atendam as formas limites e os conteúdos determinados pela Constituição. Ao Poder Judiciário, portanto, caberá, em último caso, a função de aproximar o modelo normativo existente na Constituição da prática efetiva do Estado, função esta a ele atribuída pelo próprio modelo do Estado Constitucional de direito. 
No chamado Estado Democrático Constitucional regulam-se os conflitos existentes entre os direitos fundamentais e a democracia, que podem ser diluídos mediante a concretização da autoligação que possibilita a institucionalização dos direitos humanos. Nos direitos humanos se encontra a base de legitimação para todos os poderes e a democracia apresenta-se como um processo que aponta para a realização dos direitos humanos e existe para concretizá-los (FONSECA, 2007, p. 53-54).

Neste sentido, destaca-se que "a dignidade humana é referência estrutural para o constitucionalismo mundial, a emprestar-lhe fundamento de validade, seja qual for o ordenamento, não apenas dentro, mas também fora e contra todos os Estados" (FERRAJOLI, 2002, p. 1988).

Com isso, os direitos humanos não atuam externamente como normas morais, mas como regras formais de procedimento da legislação e controle constitucional interno, tendo em vista que "[...] o Estado e a democracia nele presente são os fundamentos dos direitos humanos" (JEYCIC, 2007, p. 76).

Diante do modelo de Estado Constitucional de Direito apresentado, nota-se que para a garantia efetiva da democracia no Estado Democrático de Direito, este deve possuir mecanismos internos para a proteção dos direitos humanos. Porém, não há no Brasil uma estrutura interna que possibilite a efetiva proteção e promoção destes direitos, pois

[...] o Estado de Direito carece de instituições, de procedimentos de ação e de formas de revelação dos poderes e competências que permitam falar de um poder democrático, de uma soberania popular, de uma representação política, de uma separação de poderes, de fins e tarefas do Estado (CANOTILHO, 1999, p. 12-21).

Constata-se que a garantia dos direitos humanos é pressuposto para a garantia da democracia, pois "[...] todos os princípios e valores que primam pela justiça e paz só serão alcançados, e somente poderão ser conseguidos dentro de um ideal democrático" (JEYCIC, 2007, p. 77), o que denota a relação que se tem entre os direitos humanos e a democracia. No sistema regional Interamericano, sobre o qual se insere este estudo, há notadamente uma inter-relação entre democracia e direitos humanos ao analisar a Carta Democrática Interamericana: Art. $7^{\circ}$ A democracia é indispensável para o exercício efetivo das liberdades fundamentais e dos direitos humanos em seu caráter universal, indivisível e interdependente, consagrados nas respectivas constituições dos Estados e nos instrumentos interamericanos e internacionais de proteção. Deste modo, a democracia demonstra um dos pilares para o exercício e respeito aos direitos humanos. 
Mas diante da violação diária ocorrida, sobretudo pelo Estado, que deveria salvaguardar estes direitos, fez-se necessária a criação de mecanismos internacionais de proteção aos direitos humanos, como o sistema regional Interamericano, mas essa tutela internacional ainda compõe o sistema global e os demais regionais.

\section{O PODER POLÍTICO}

O poder faz parte das relações cotidianas, difícil imaginar uma situação onde não exista uma relação de poder, pois sempre há a influência de um individuo ou de um grupo na maioria das situações sociais. Entretanto, o presente estudo visa analisar a relação do poder na política, ou seja, o poder político. Este poder trata-se daquele que uma pessoa ou um grupo exerce sobre os demais. O grande precursor da ideia de poder foi Marx Weber e é a partir dele que se inicia qualquer estudo sobre poder político.

Weber estabelecia relações de mando e obediência e que se encontram caracteristicamente na política, essa relação se fundamenta em bases materiais ou até mesmo no simples hábito de subordinação e também, na legitimidade. Este pensador estabeleceu três tipos de poder sendo esses: o Poder legal, Poder tradicional e o Poder carismático. Estes tipos de poder, também são objeto do estudo de Nunes (1991, p. 7879), sendo que a existência do poder legal é de caráter racional, que teria sua legitimidade designada na lei. O segundo seria decorrente das tradições, crenças e costumes. O terceiro tem como característica o valor pessoal do homem. Para Nunes esses tipos de poder muito raramente são encontrados, quando o são, estão na realidade histórica.

Assim, o Poder legal constituiria a fonte do Poder, visto que decorre da lei, da legitimidade de ordenamentos jurídicos que acabam por definir as funções do detentor do Poder, bem como daquele que está subordinado a ele, os cidadãos. No tradicional se verificou que o Poder decorre de uma tradição, a ordem é comunicada aos súditos. E como já fora dito, o poder carismático é então um poder heroico, exemplar, o comando é exercido por um verdadeiro líder. Ao contrário do que pensa Nunes, no qual esses tipos de poder são raramente encontrados, observa-se a presença do Poder legal na modernidade, quanto aos outros tipos pode verificar a sua existência em tempos passados, através da via histórica.

Após os estudos sobre a concepção do poder realizados por Weber, outros estudos começaram a surgir, como o de Parsons (BOBBIO, 1998, p. 941 in PARSONS, 
1975) que define o Poder sob a ótica de uma propriedade do sistema político, ancorado na legitimação e no uso da violência, em suas palavras verifica-se então o Poder

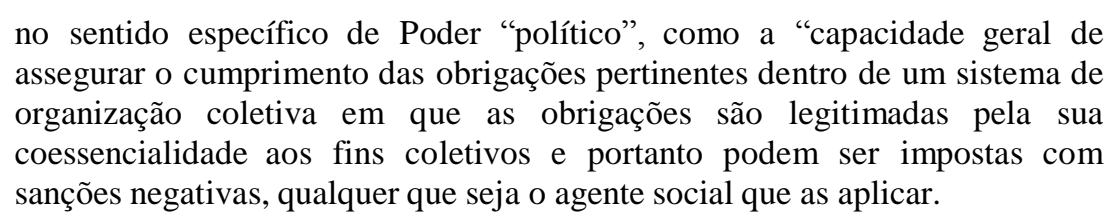

Com relação ao significado de política, Aristóteles foi o fundador da ideia. Segundo ele política se referia a tudo o que estava ligado a cidade, assim, percebe-se que sua obra A Política também deve ser vista como uma teoria de função do Estado e ciência do Governo, onde poder e política caminham juntos. Mas, afinal, o que é o poder político? O poder político é o exercício do poder de um homem sobre o outro, e essa relação pode ser estabelecida de diversas maneiras "como relação entre governantes e governados, entre soberano e súditos, entre Estado e cidadãos, entre autoridade e obediência, etc.” (BOBBIO, 1998, p. 954).

Deste modo se verifica que o poder político tem como elemento essencial o uso da força, seria assim, impossível falar em poder político sem abordar a força e as influências que ela exerce na conjectura atual política. Importantes mestres em ciência política, afirmam que sem a força seria impossível até mesmo se falar em existência do Estado. Neste viés, como o poder político correlacionado com o uso da força se faz presentes nos dias atuais? Esta e outras perguntas serão abordadas nos tópicos seguintes, de modo a analisar as proposições do poder político no Estado Democrático.

\subsection{O Poder Político: uma relação de força e dominação}

Tendo em vista que a ideia de poder também está relacionada com o sentido de potência, qual consiste realizar um papel determinado, ainda que não possa vir a praticar este ato. Desta feita, a potência poderá a vir se tornar uma ação ou ser a própria ação, poder de realizar algo. Sobre potência alude Lebrun citando Weber que "Potência (Macht) significa toda oportunidade de impor a sua própria vontade, no interior de uma relação social, até mesmo contra resistências, pouco importando em que repouse tal oportunidade" (1981, p. 4).

Todavia, fala-se em poder e não em potência, pois o poder possui um elemento suplementar, este elemento é a força. Tanto a força quanto a ideologia são de extrema importância para compreender as relações de poder e dominação, afinal, o poder implica uma ordem e obediência, revelando assim a tradução do que Weber chama de 
Herrschaft, ou seja, domínio. A dominação segundo Weber é "a probabilidade de que uma ordem com um determinado conteúdo específico seja seguida por um dado grupo de pessoas". (1981, p. 5). Partindo dessa breve noção de que o poder constitui uma potência, ou seja, impor a sua própria vontade e a dominação seria fazer impor uma ordem que seja obedecida por um grupo de pessoas, pode-se ter uma breve noção do que seja o poder, situando este como sendo uma vontade imposta para que um grupo ou a massa siga determinada ordem, deste modo, poder também é dominação.

A dominação pode ser exercida através da ideologia e da força, elementos estes que constituem o Poder, sendo que é o Estado quem exerce a função essencial da organização das relações ideológicas, da ideologia dominante e também da força, caracterizando assim o Poder Político. Assim, observa-se que à priori o Poder Político nada mais era do que o uso da violência, como pronuncia Tsé-Tung (2013, p. 260) “o Poder Político vem do cano de um revólver".

Ao decorrer dos tempos, essa ideia de que o objeto do poder seria somente a força física veio sendo deixada de lado, surgiu novos parâmetros como a ideologia. A ideologia e a força como observado são elementos bastante próximos, sendo que é a ideologia que legitima a força como ensina Poulantzas (2000, p. 27), no qual entende que o Estado não pode usar somente desses meios. E ainda, ao que tange a ideologia, segundo o autor, o Estado usa de diversos elementos de ideologização em forma de discursos com uma plateia determinada, isso não passaria de táticas políticas, lembrando que, é a política a formar pela qual o Estado se torna o detentor do poder.

O Estado não pode sancionar e reproduzir o domínio político usando como meio exclusivo a repressão, a força ou a violência 'nua', e sim, lançando mão diretamente da ideologia, que legitima a violência e contribui para organizar um consenso de certas classes e parcelas dominadas em relação ao poder público. (POULANTZAS, 2000, p.27).

Assim, para Poulantzas, a ideologia é que legitima a força, sendo que esta ideologia é exercida através de discursos, estes discursos são direcionados a certas classes, o discurso jamais será único, ele sempre será diversificado conforme sua platéia, tendo ainda como elemento recente a dominação, e é através desses discursos diversificados conforme cada classe ou platéia que a dominação se fará presente.

Conforme os tipos de dominação percebe-se que no Estado Democrático atual, observa sua existência desde a fundação deste regime. A dominação se faz presente tanto no aspecto da legalidade, visto que, são os próprios governantes que não raramente acabam criando leis, quanto a tradição, a dominação já está enraizada desde a 
muito tempo e é devido à falta de conhecimento. Ocorre assim, a conformidade de uma subordinação pelos verdadeiros legitimados ao exercício do poder: o povo. Em face disto, enquanto essa cultura política de dominação permanecer, o (i)legítimo é quem continuará exercendo o poder conforme suas vontades.

Ao tratar sobre a ideia de Poder, muitos pensadores proclamam que a causa do Poder seria o uso exclusivo da força, contudo, esta tese é causa de divergências, para Azambuja "nenhum regime, nenhum governo, por mais despótico, pode se basear exclusivamente na força" (2008, p. 83). Essa ideia pode ser corroborada com o pensamento de Poulantzas, na qual o Estado usa ainda de meios como a ideologia, e exerce a dominação através de seus discursos. Neste sentido, Azambuja (2008, p.84) bem expõe o uso da violência na modernidade, sendo que

\footnotetext{
Nas sociedades modernas, a força, a coerção material é substituída em grande parte por outra força maior: é a persuasão, a coação psicológica. Esta é permanentemente, multiforme, praticamente irresistível para a maioria. É a propaganda: nas ruas, nos jornais, nas escolas, na família...em toda parte. É a maior força na sociedade atual.
}

Portanto, percebe-se que grandes pensadores faziam menção ao Poder Político como sendo o uso exclusivo da força, ou da força corroborada com a ideologia. Todavia, na sociedade atual essa força do Poder Político não é mais sinônimo de violência, mas sim, de um domínio psicológico, realizado através dos discursos e dos meios de comunicação.

\subsection{Os legitimados ao exercício do Poder na Democracia}

Para se exercer o Poder, devem existir partes legitimadas para tanto, é o que se chamam no Estado Democrático de cidadãos, os cidadãos são indivíduos que possuem legitimidade para escolher representantes para o exercício do Poder. Esse processo de escolha se dá através da eleição, sendo adotado um sistema majoritário, ou seja, a decisão da maioria se sobrepõe sobre da minoria.

Pela regra da maioria, o governo estava obrigado a servir aos interesses de todos e dar-lhes proteção, de modo que em determinadas circunstâncias os direitos e os interesses da minoria seriam sacrificados, mas se devia proteger esta contra a tirania da maioria. (COSTA. 2012, p. 218).

Nesta perspectiva o Estado Democrático de Direito é o poder formal da maioria de eleger um representante, de modo a não afetar a minoria, tendo em vista que, na Democracia, o poder para "ser obedecido e permanecer, precisa absolutamente do consentimento da maioria dos membros do grupo social” (AZAMBUJA, 2008, p. 83). 
Contudo, como dizer que a regra da maioria tem como princípio não afetar os direitos da minoria se ela está "obrigada" a se subordinar ao governo da maioria? Assim, podese perceber que a Democracia nada mais é do que o governo exercido pelos representantes da maioria, onde a minoria é a parte mais fraca, e possui o dever de se subordinar as imposições e forma de governo da maioria.

Deste modo, como ocorre a acomodação da minoria ao se deparar com essa situação? A conformação vem da força, como já estudado. Bobbio já afirmara que o Estado pode renunciar a várias coisas, como da ideologia, do poder econômico, da liberdade, contudo o Estado jamais poderá deixar de renunciar ao poder da força, visto que sem ele deixará de ser Estado (NUNES, 1991, p. 74). Essa força nada mais é do que a força da Lei, visto que está é um dos alicerces do Estado Democrático de Direito.

O Estado democrático pode ainda ser manipulado, visto que a lei seria um instrumento desta manipulação, bem como que ao decorrer do tempo no Estado Democrático de Direito, as leis se modificam constantemente, podendo gerar novos rumos ao Estado. É através dessa dominação que ocorre então a subordinação, mas não somente através dela, considerando que

\begin{abstract}
Se perguntarmos porque uns indivíduos se sujeitam a outros, a resposta, segundo Weber, está no conhecimento tanto dos meios externos utilizados pelo poder para fazer executar suas ordens, como nos motivos internos pelos quais os súditos aceitam tais instruções e com elas se conformam. (NUNES, 1991, p. 77).
\end{abstract}

Ao que tange a "representatividade" nos Estados Democráticos, verifica-se que ela é apenas formal, pois, na verdade se elegem representantes para que estes se tornem os verdadeiros detentores do Poder. Assim decorrem os problemas. Ao se eleger um candidato não se sabe se este realmente atenderá aos anseios da sociedade que o elegeu, no fim, tanto a maioria quanto a minoria ficam a mercê e subordinados aos governantes. Diante disto, como se verificar a existência da real democracia? Deste modo asseverou Rousseau que "nunca existiu uma verdadeira democracia nem jamais existirá" (NUNES, 1991, p. 76).

E ainda, importante mencionar o pensamento de Habermas, revelando que

Os críticos têm razão em afirmar que a regra da maioria, enquanto tal, é absurda. Porém, ela nunca é pura e simplesmente uma regra da maioria...É importante saber quais são meios através dos quais uma maioria chega a ser maioria: os debates anteriores, a modificação dos pontos vista para levar em conta as opiniões das minorias...Noutras palavras, a coisa mais importante consiste em aprimorar os métodos e condições do debate, da discussão e da persuasão. (HABERMAS 1997, p.27 in DEWEY 1954, p. 207-208). 
Esses meios citados por Habermas fazem parte da política, pois, é através da persuasão que a maioria se torna uma maioria. Contudo, como já fora evidenciado, o grande problema está na dominação dos discursos, ocorrendo que na democracia, a dominação toma conta dos legitimados á escolher os representantes do povo, deste modo, acabam assim, exercendo apenas um poder formal, se é que se pode chamar isso de poder. Portanto, no Estado Democrático, a real legitimidade do Poder está nas mãos dos governantes onde os governados pouco conseguem fazer, mesmo havendo meios para manifestar a sua indignação, pois o governante detém a força, não somente a força física, mas, a mais terrível que é a força psíquica. Assim, esta longe de se dizer que vivemos em um Estado Democrático, e muito menos se pode afirmar que a democracia seria a verdadeira solução para todos os problemas.

\subsection{A Sustentabilidade}

O desenvolvimento de uma Nação deve ter como fundamento o princípio da Dignidade Humana, considerado como capaz para proporcionar um ambiente com qualidade para todos. No entendimento de Kliksberg,

Há uma revalorização no novo debate de aspectos não incluídos no pensamento econômico convencional. Instalou-se uma potente área de análise em vertiginoso crescimento que gira ao redor da idéia de 'capital social'. Um dos focos dessa área, por sua vez com sua própria especificidade, é o reexame das relações entre cultura e desenvolvimento. Como assinala Lourdes Arizpe (1998), 'a cultura passou a ser o último aspecto inexplorado dos esforços que se desenvolvem em nível internacional, para fomentar o desenvolvimento econômico'. Enrique V.Iglesias (1997) sublinha que se abre neste reexame das relações entre cultura e desenvolvimento um vasto campo de grande potencial. Ressalta: 'há múltiplos aspectos na cultura de cada povo que podem favorecer seu desenvolvimento econômico e social; é preciso descobri-los, potencializá-los, e apoiar-se neles, e fazer isto com seriedade significativa rever a agenda do desenvolvimento de um modo que resulte, posteriormente, mais eficaz, porque tomará em conta potencialidades da realidade que são de sua essência e que, até agora, foram geralmente ignoradas'. (2001, p. 107).

O que a realidade tem demonstrado é o fato de que o desenvolvimento econômico está atrelado às áreas política e social. O que ocorrer em uma delas afetará as demais. Para Sachs (1986, p. 55), “[...] o verdadeiro desafio da crise é o de assumir-se conscientemente a modulação da demanda social, sem, entretanto, perder de vista as relações existentes entre demanda social, as modalidades da oferta e o meio ambiente." 
Amartya Kumar Sen (2000, p. 23) investiga "o processo de desenvolvimento integrando considerações econômicas, sociais e políticas". Esta relação do desenvolvimento numa abordagem ampla,

[...] permite a apreciação simultânea dos papéis vitais, no processo de desenvolvimento, de muitas instituições diferentes, incluindo mercados e organizações relacionadas ao mercado, governos e autoridades locais, partidos políticos e outras instituições cívicas, sistema educacional e oportunidade de diálogo e debate abertos (incluindo o papel da mídia e outros meios de comunicação).

Essa abordagem nos permite ainda reconhecer o papel dos valores sociais e costumes prevalecentes, que podem influenciar as liberdades que as pessoas desfrutam e que elas estão certas ao prezar. Normas comuns podem influenciar características sociais como a igualdade entre os sexos, a natureza dos cuidados dispensados aos filhos, o tamanho da família e os padrões de fecundidade, o tratamento do meio ambiente e muitas outras.[...]. (2000, p. 23).

Diante do exposto é salutar abordar o tema "desenvolvimento" sob estas outras dimensões, que impliquem em novas políticas capazes de impulsionar o fortalecimento das sociedades democráticas para atingir o real desenvolvimento dos seus povos com dignidade e melhor qualidade de vida. Grande desafio a ser enfrentado está em transformar efetivamente as liberdades em direitos, bem como garanti-las por meio de um processo democrático. A escolha das prioridades que pareçam mais adequadas ao bem-estar geral, todavia, deve partir da comunidade e não estar somente vinculada às decisões políticas do legislador. As liberdades estão, desta forma, relacionadas à questão dos direitos do homem,

[...] os direitos humanos são compatíveis com a democracia, mas representam, simultaneamente, uma desconfiança do processo democrático. São democráticos na medida em que asseguram a existência e desenvolvimento de pessoas capazes de manter o processo democrático em funcionamento, pois sem eles a democracia fica reduzida a mera figura retórica. Por outro lado, com a vinculação também do legislador, os direitos fundamentais são subtraídos do poder decisório das maiorias parlamentares, o que se reflete na aludida desconfiança na democracia.

Qualquer comunidade humana tem o direito de escolher o seu destino. Para isto existe a democracia. Os direitos humanos apenas asseguram que a comunidade será verdadeiramente humana e democrática. (ALEXY, 1999, p. 65-66).

Segundo Sen (2000, p. 19), “[...] a condição de agente livre e sustentável emerge como um motor fundamental do desenvolvimento. A livre condição de agente não só é, em si, uma parte "constitutiva" do desenvolvimento, mas também contribui para fortalecer outros tipos de condições de agentes livres [...]." 
Os processos de libertação e de democratização comungam de elementos comuns, como a percepção da possibilidade da inovação, que se traduz na participação ampliada de atores sociais de diversos tipos em processos de tomada de decisão. Estes processos, por partirem especialmente do âmbito local, incluem temas não considerados pelo sistema político, o que acaba redefinindo identidades, vínculos e aumentando a participação social (SANTOS, 2002). Além destes aspectos abordados, o desenvolvimento engloba a proteção do meio ambiente fundamental para a harmonia do planeta e para a concretização de um desenvolvimento com sustentabilidade.

$\mathrm{Na}$ tentativa de superar os obstáculos, Sachs (1993) destaca a importância de considerar as cinco dimensões de sustentabilidade quando se pretende planejar o desenvolvimento. Segundo este autor, as dimensões que necessitam ser analisadas são: a) Sustentabilidade social ${ }^{1}$, considerada como a consolidação de um processo de desenvolvimento baseado em outro tipo de crescimento e orientado por outra visão sobre o que seja a boa sociedade. Possui como finalidade a construção de uma civilização com eqüidade na distribuição da renda para melhorar os direitos de grandes massas, em que seja mais importante o ser do que o ter; $b$ ) Sustentabilidade econômica ${ }^{2}$, possibilitada por uma alocação e gestão mais eficientes dos recursos e por um fluxo regular do investimento público e privado; c) Sustentabilidade ecológica ${ }^{3}$, necessária para que as demais dimensões atinjam seus objetivos. Ela pode ser realizada por meio de projetos que limitam o consumo de combustíveis fósseis e de outros recursos e

\footnotetext{
${ }^{1 ، " E m ~ r e l a c ̧ a ̃ o ~ a ̀ ~ s u s t e n t a b i l i d a d e ~ s o c i a l ~ o ~ d e s e n v o l v i m e n t o ~ d e v e ~ s e r ~ a n a l i s a d o ~ e m ~ s u a ~}$ multidimensionalidade, abrangendo todo o espectro de necessidades materiais e não-materiais, como corretamente enfatiza o PNUD no Relatório sobre o Desenvolvimento Humano, ainda que tal ênfase não se reflita no reducionismo de seu índice de desenvolvimento humano.” (SACHS, 1993, p. 25).

"Uma condição fundamental para isso é superar as atuais condições externas, decorrentes de uma combinação de fatores negativos já mencionados: o ônus do serviço da dívida e do fluxo líquido de recursos financeiros do Sul para o Norte, as relações adversas de troca, as barreiras protecionistas ainda existentes nos países industrializados e, finalmente, as limitações do acesso à ciência e à tecnologia. A eficiência econômica deve ser avaliada mais em termos macrossociais do que apenas por meio de critérios de lucratividade microempresarial." (SACHS, 1993, p. 25).

${ }^{3}$ A sustentabilidade ecológica abrange vários aspectos, segundo Sachs (1993, p. 25-26):

“- aumento da capacidade de carga da Espaçonave Terra por meio da engenhosidade ou, em outras palavras, intensificação do uso dos recursos potenciais dos vários ecossistemas - com um mínimo de dano aos sistemas de sustentação da vida - para propósitos socialmente válidos;

- limitação do consumo de combustíveis fósseis e de outros recursos e produtos facilmente esgotáveis ou ambientalmente prejudiciais, substituindo-os por recursos ou produtos renováveis e/ou abundantes e ambientalmente inofensivos;- redução do volume de resíduos e de poluição, por meio da conservação e reciclagem de energia e recursos;

- autolimitação do consumo material pelos ricos e pelas camadas sociais privilegiadas em todo o mundo;

- intensificação da pesquisa de tecnologias limpas e que utilizem de modo mais eficiente os recursos para a promoção do desenvolvimento urbano, rural e industrial;

- definição das regras para uma adequada proteção ambiental, concepção da máquina institucional, bem como escolha do conjunto de instrumentos econômicos, legais e administrativos necessários para assegurar o cumprimento das regras."
} 
produtos facilmente esgotáveis ou ambientalmente prejudiciais, substituindo-os por recursos ou produtos renováveis e/ou abundantes e ambientalmente inofensivos; redução do volume de resíduos e de poluição; autolimitação do consumo material pelos países ricos e pelas camadas sociais privilegiadas em todo o mundo; intensificação da pesquisa de tecnologias limpas; definição das regras para uma adequada proteção ambiental; d) Sustentabilidade espacial ${ }^{4}$, relacionada a uma configuração rural - urbana mais equilibrada e a uma melhor distribuição territorial de assentamentos humanos e atividades econômicas; e) Sustentabilidade cultural $^{5}$, em busca das raízes endógenas dos modelos de modernização e dos sistemas rurais integrados de produção.

Destaca-se a importância da evolução conjunta destas dimensões para que surtam efeitos. Faz uma análise da sustentabilidade social como sendo aquela que melhora a qualidade de vida da sociedade com a distribuição de renda justa e igualdade no acesso a recursos e serviços sociais. Da sustentabilidade cultural, como a que mantém a diversidade cultural mediante projetos integrados ${ }^{6}$, e em relação à sustentabilidade ambiental, enfatiza a necessidade da preservação da capacidade de suporte dos ecossistemas. Quanto à sustentabilidade política dá ênfase para a construção da cidadania e fortalecimento das instituições públicas.

Além das dimensões sobre a sustentabilidade existem premissas relacionadas à adoção de uma forma viável de desenvolvimento. São questões em construção e discussão. Algumas, devido a sua importância, aparecem com maior freqüência, como:

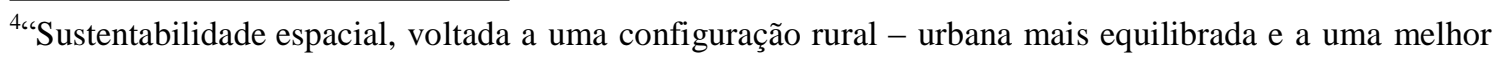
distribuição territorial de assentamentos humanos e atividades econômicas, com ênfase nas seguintes questões:- concentração excessiva nas áreas metropolitanas;

- destruição de ecossistemas frágeis, mas vitalmente importantes, por processos de colonização descontrolados;- promoção de projetos modernos de agricultura regenerativa e agroflorestamento, operados por pequenos produtores, proporcionando para isso o acesso a pacotes técnicos adequados, ao crédito e aos mercados;- ênfase no potencial para industrialização descentralizada, associada a tecnologias de nova geração (especialização flexível), com especial atenção às indústrias de transformação de biomassa e ao seu papel na criação de empregos rurais não-agrícolas; nas palavras de M. S. Swaminathan, 'uma nova forma de civilização, baseada no uso sustentado de recursos renováveis, não é apenas possível, mas essencial' [...].- estabelecimento de uma rede de reservas naturais e de biosfera para proteger a biodiversidade." (SACHS, 1993, p. 26).

${ }^{5}$ Sustentabilidade cultural, em busca das raízes endógenas dos modelos de modernização e dos sistemas rurais integrados de produção, privilegiando processos de mudança no seio da comunidade cultural e traduzindo o conceito normativo de ecodesenvolvimento em uma pluralidade de soluções particulares, que respeitem as especificidades de cada ecossistema, de cada cultura e de cada local (SACHS, 1993).

${ }^{6}$ Consiste na manutenção da diversidade cultural, capacidade de elaboração de um projeto nacional integrado, autoconfiança combinada com abertura para o mundo.

Projetos integrados são apresentados por Boaventura de Sousa Santos (2002), onde os atores locais se unem e acabam por influenciar as políticas públicas na transformação e melhoria da sociedade. Exemplos: os micromovimentos na Índia, as lições de Kerala, na Índia, a mulher em Moçambique e outros.
} 
a) Eqüidade intrageração ${ }^{7}$ : o desenvolvimento sustentável implicaria eqüidade intrageração no uso dos estoques de capital natural e na distribuição de renda, problema que pode ser abordado sob vários ângulos, como o consenso no fato de serem as populações empobrecidas (carentes de saneamento, limpeza urbana, poluição...) as mais afetadas pela degradação ambiental. Também existe a necessidade da revisão dos padrões de consumo para que os estoques de capital natural sejam disponibilizados aos países empobrecidos, elevando a qualidade de vida de suas populações. Construir um desenvolvimento sustentável se torna inviável diante de tanto desequilíbrio social; b) Eqüidade Intergerações: é pensar a sustentabilidade com respeito para as futuras gerações. Pode-se dizer que por questão de justiça, as futuras gerações devem ter acesso a, pelo menos, o mesmo nível de capital natural que as gerações antecedentes. Esta eqüidade intergerações é um processo de justiça, pois muitas vezes as perdas ambientais são irreversíveis, provocam extinções e privam as gerações futuras deste capital natural perdido; c) Irreversibilidades: é a tentativa de evitar que o futuro seja pior que o presente, o que significaria a ausência de sustentabilidade. Os impactos ambientais só poderão ser aceitos com a certeza de sua reversibilidade, ou com um custo ambiental que possa ser absorvido pelas futuras gerações. Assim a sociedade deve ter em mente os riscos de irreversibilidade que ocorrem ao conduzir o processo de desenvolvimento, pois, se algum erro for cometido neste sentido não haverá como revertê-lo. Florestas tropicais não podem ser recriadas em toda a sua biodiversidade; áreas desertificadas constituem-se, muitas vezes, em desertos eternos; contaminação de águas subterrâneas pode inviabilizar completamente seu uso, e outros; d) Incertezas: em relação à análise do desenvolvimento sustentável, é preciso considerar também os graus de incerteza relacionados às transformações ambientais para a necessidade de manutenção dos estoques do capital natural. Para tanto a própria sociedade necessita ter a certeza de seu papel como agente transformador; e) Resiliência ${ }^{8}$ : refere-se à capacidade e limite de os sistemas sociais e naturais retornarem ao estado anterior, assim que a pressão cesse.

\footnotetext{
${ }^{7}$ Outro fato se relaciona com as diferenças nos níveis de consumo entre os povos. As diferenças são tão expressivas que os países empobrecidos levariam 127 anos para alcançar o nível de renda de 1986 dos países enriquecidos (LUMMIS apud MERICO, 2002).

Também a exclusão social, que é fruto de um modelo econômico que gera crescimento de forma desconectada do atendimento às necessidades humanas. Da mesma forma, a distribuição dos benefícios gerados pelos atuais padrões de desenvolvimento tem gerado profundas injustiças sociais, atuando, inclusive, como causa de destruição e rompimento dos ecossistemas. O desenvolvimento econômico mundial, além de gerar profunda degradação ambiental natural, trouxe também uma injusta distribuição dos benefícios desse desenvolvimento, com um crescimento significativo da pobreza.

${ }^{8}$ É necessário saber que nível de pressão pode ser aplicado sobre um assentamento humano, região ou ecossistema, sem que suas funções e serviços ambientais fiquem irreversivelmente comprometidos.
} 
Tanto sociedades quanto ecossistemas podem não conseguir retornar ao estado anterior, caso a pressão seja longa e a capacidade de resistir às pressões não seja suficiente para retornar à situação de origem sem que mudanças irreversíveis ocorram; f) Justiça com os outros seres vivos: existem direitos dos seres vivos não-humanos que constituem o direito de existência que todo ser vivo possui, independentemente de sua utilidade para os próprios humanos. Quando a sociedade destrói capital natural, está destruindo habitats e reduzindo a biodiversidade. Quanto maior o estoque de capital natural, mais habitats poderão ser ocupados por seres vivos, mantendo a diversidade genética. A manutenção dos direitos de existência de todos os seres vivos não-humanos é uma obrigação moral e ética coerente com os princípios da sustentabilidade e deve ser levada a sério pela atual civilização (MERICO, 2002).

Os desafios para alcançar um desenvolvimento com sustentabilidade são imensos e passam pelos padrões dominantes de modelo e consumo que estão se tornando globalizados, causando mais devastação ambiental de ecossistemas mantenedores de vida e perda massiva da biodiversidade. O desenvolvimento sustentável deve ser equilibrado, levando em conta o aspecto econômico, ecológico e social. Atualmente a globalização ${ }^{9}$ está priorizando o desenvolvimento econômico à custa do desenvolvimento e conservação social e ecológica.

A literatura referente ao termo desenvolvimento sustentável revela alguns momentos importantes de sua expansão. Para Montibeller-Filho é a partir da década 80 do século XX que o termo desenvolvimento sustentável começou a ser difundido:

\footnotetext{
É uma expressão de influência anglo-saxônica (sustainable development), utilizada primeiramente pela União Internacional pela Conservação da Natureza (correspondente em inglês a IUCN). A tradução oficial francesa para o conceito é développement durable, equivalendo em português a desenvolvimento durável e bastante próximo ao de sustentável. $\mathrm{Na}$ conferência mundial sobre a conservação e o desenvolvimento da IUCN (Ottawa, Canadá, 1986), o conceito desenvolvimento sustentável e eqüitativo foi colocado como um novo paradigma, tendo como princípios:

- integrar conservação da natureza e desenvolvimento;

- satisfazer as necessidades humanas fundamentais;

- perseguir eqüidade e justiça social;

- buscar a autodeterminação social e respeitar a diversidade cultural;
}

\footnotetext{
${ }^{9}$ Em relação à globalização existem historicamente várias teorias, ligadas a épocas remotas da humanidade. Ela é um processo. Para Silva (2000), é quase consenso que a globalização, como fenômeno que permeia nossa época, situa-se em momento mais próximo, no século XVI, com o surgimento do modo de produção capitalista, época que simboliza o fim da Idade Média e o começo da Idade Moderna.

Para Santos (apud SILVA, 2000, p. 39), “a globalização deixa de ser uma simples palavra para se tornar um paradigma do conhecimento sistemático da economia, da política, da ciência, da cultura, da informação e do espaço." Segundo Santos (2002, p. 13), "a globalização neoliberal é hoje um fator explicativo importante dos processos econômicos, sociais, políticos e culturais das sociedades nacionais."
} 
- manter a integridade ecológica. (2001, p. 47-48).

Nesse sentido a importância da Democracia para conseguir implementar as mudanças no poder político visando a sustentabilidade em todos os seus aspectos.

\section{O ESTADO DEMOCRÁTICO DE DIREITO COMO LIMITADOR DO PODER POLÍTICO E A BUSCA PELA SUSTENTABILIDADE}

Sabe-se que o poder político, tem como elemento principal a força, não que isto significa dizer que o poder político sempre é exercido através da força física. Principalmente, no Estado atual o poder político vem sendo exercido de diversas formas, no qual caracteriza ainda, a manipulação e domínio da sociedade. No Estado Democrático de Direito, essa força na qual impõe a subordinação do povo vem da própria lei, assevera Bakunin que "apesar da constituição política ser igualitária, é a burguesia que governa, e é o povo, operários e camponeses, que obedecem suas leis".

Neste aspecto como citado por Bakunin, qual seria os camponeses, na sociedade atual é o povo com menos patrimônio e grau de instruções educacionais e políticas, e a burguesia consiste naqueles que possuem um maior patrimônio e às vezes, um maior conhecimento político e acabam fazendo uso deste para dominar a sociedade. Assim, os mais instruídos, consequentemente os detentores de maior saber e poder elaboram as leis, as quais subordinam o povo.

O principal objetivo do Estado Democrático de Direito, como o próprio nome já diz nada mais é do que uma junção do Estado Democrático com o Estado de Direito. Contudo mister se faz analisá-los de modo distinto, apesar de que vários doutrinadores não conseguirem fazer a distinção entre um e outro. Com relação ao Estado de Direito no qual pressupõe a subordinação de todo poder ao direito, ou seja, o governante esta submetido ao direito mesmo ele criando ou não as leis.

No entanto, segundo Nunes (1991, p. 101) é necessário que este Estado de Direito passe de um Estado formal e se torne um Estado material, ou seja, que concretize os anseios da sociedade. Para que esse Estado passe do formal para o material, é preciso a interferência da democracia, caracterizando assim o Estado Democrático de Direito, instituído através de uma Constituição. Entretanto como questiona o autor, como saber se as leis e a Constituição são legitimas?

Se é certo que o Estado de direito democrático, ele próprio, pode ser manipulado, vez que o direito pode ser utilizado como instrumento dessa manipulação, certo é também que a circularização do regime democrático, 
desde que duradoura, tende a legitimar ou a modificar as normas estabelecidas (NUNES, 1991, p.101).

Sendo assim, percebe-se que se vivencia uma constante dominação, e o que na realidade deveria ser usado como meio de limitar o Poder Político, qual seja, a elaboração de leis, uma Constituição rígida que respeite os ideais democráticos, o contrário pode ocorrer, pois, como já conhecido, a dominação deixa os povos á mercê do poder político, visto que exerce sua força de dominação até mesmo sobre a forma de Estado democrático.

Diante do exposto, valem as considerações realizadas por Zimmerman (2002, p. 64-65) sobre algumas características desse Estado de modo a correlacionar os ideais de democracia e de limitação do poder estatal. Dentre as importantes características apontadas, destaca-se uma qual seja o "império da lei", no sentido de legalidade que se sobrepõe a vontade governamental. Assim, segundo ele, uma das principais características do Estado Democrático de Direito é a imperatividade da lei sobre os atos dos governantes.

Tendo em vista que é o governante quem exerce o poder, sendo que o cidadão possui apenas a legitimidade formal, qual consiste em eleger o detentor do poder, mas, após as eleições o cidadão perde sua legitimidade. Deste modo, alguns Estados possuem mecanismos próprios para que se exijam algumas prestações ou fiscalize os abusos de poder, mas, com um povo onde a dominação impera poucas vezes se observam a utilização desses mecanismos. Frente a essas considerações, pode-se dizer que as leis limitam o poder político? Como é estabelecido esse poder, sendo que os próprios governantes é que elaboram as leis? Sobre essas questões, importante as considerações feitas por Bobbio:

\begin{abstract}
Por inclusividade se entende a possibilidade de intervir, de modo imperativo, em todas as esferas possíveis da atividade dos membros do grupo e de encaminhar tal atividade ao fim desejado ou de a desviar de um fim não desejado, por meio de instrumentos de ordenamento jurídico, isto é, de um conjunto de normas primárias destinadas aos membros do grupo e de normas secundárias destinadas a funcionários especializados, com autoridade para intervir em caso de violação daquelas. Isto não quer dizer que o poder político não se imponha limites. Mas são limites que variam de uma formação política para outra. (BOBBIO, 1998, p. 957).
\end{abstract}

Percebe-se que segundo Bobbio, seja possível a limitação do poder através de instrumentos do ordenamento jurídico, instrumentos esses que estão presentes de forma explícita no Estado Democrático de Direito. Contudo, ainda de acordo com o que foi dito, os limites do poder político, variam conforme a formação política de cada Estado. 
Deste modo, verifica-se que as bases políticas brasileiras, estão longe de serem tão bem estruturadas de modo a vir limita-lo. E ainda, Dahal ao fazer uma distinção entre o modelo de assembléias e democracia representativa, expõe

A lei do tempo e dos números: quanto mais cidadãos uma unidade democrática contém, menos esses cidadãos podem participar diretamente das decisões do governo e mais eles têm de delegar a outros essa autoridade. (DAHAL, Robert, p. 125).

Para o autor o número de cidadãos legitimados para participar de eleição seria como um limite ao poder político, assim, o entende que quanto menor a localidade que habita esses cidadãos, menor é a delegação de poder ao representante, todavia, quanto maior for a localidade, maior serão os problemas importantes, havendo assim uma maior necessidade de delegação do poder de decisão ao representante. Neste sentido, enquanto houver um governo, onde alguns homens detenham mais poder do que o outro, esse poder dependerá da dimensão que ele é exercido. Conforme Habermas (1997, p.232-233), também pode indagar que

[...] no final das contas, todo o direito o direito deve emanar da vontade soberana do legislador político. No final de tudo, a legislação, a ratificação e a aplicação das leis passam a ser momentos no interior de um único processo circular regulado politicamente; e elas continuam assim, mesmo quando se diferenciam institucionalmente de acordo com poderes do Estado.

Portanto, visto que no Estado Democrático de Direito, decorre da lei a legitimidade para que se faça a escolha de representantes, o exercício do poder. Assim, a lei parte de relações políticas, deste modo o Estado esta sempre impondo suas vontades e seu poder, tanto as limitações, restrições e benefícios concedidos aos representantes também decorrem da força da lei. E tudo isso, tanto as eleições, a criação de leis, domínio e Estado Democrático, não passam então de relações táticas políticas. Desta forma, diante de tantos enigmas decorrentes de uma "suposta" democracia, cabe analisar se uma futura democratização do poder político seria capaz de resolve-los.

\subsection{Cultura Política e Educação para a Cidadania}

Com relação ao já analisado até o momento, verifica-se que a democracia ainda não está inteiramente concretizada e nem mesmo a cidadania, principalmente no que tange a participação política. Nesta perspectiva, não se pode perder de vista também, que a cultura faz parte da política, sendo essencial seu estudo para que se possa chegar em uma conclusão sobre a legitimidade do cidadão propor emenda constitucional e se a atual cultura política traz benefícios ou não para a Democracia e sociedade. 
O que não podemos fazer é discutir sobre cultura ignorando as relações de poder dentro de uma sociedade ou entre sociedades. Notem bem: o estudo da cultura não se reduz a isso, mas esta é uma realidade que sempre se impõe. Assim é porque as próprias preocupações com cultura nasceram associadas as relações de poder (SANTOS, 2006, p. 80).

Desta forma, observa-se que a cultura política é extremamente importante para analisar as implicações decorrentes da suposta e futura aprovação da PEC 286/2013, sendo que atualmente infelizmente o que se presencia é uma grande crise na cultura política, uma vez que o Estado usa de meios de ideologização para com a sociedade de modo a "influenciar" cada indivíduo a colaborar com os interesses do Estado, sendo que estes deveriam em primeiro lugar ter em vista o bem comum da sociedade.

Conforme esses meios de ideologização e os chamados discursos que não passam de táticas políticas (POULANTZAS, 200 p.27). Também se percebe que o Estado, em muitas vezes não pretende investir em algo tão importante, na educação para a cidadania, com relação a este aspecto destaca-se que:

Um dos trechos mais exemplares a este respeito é o que se encontra no
capítulo sobre a melhor forma de governo das Considerações sobre o
governo representativo de John Stuart Mill, na passagem em que ele divide
os cidadãos em ativos e passivos e esclarece que, em geral, os governantes
preferem os segundos (pois é mais fácil dominar súditos dóceis ou
indiferentes), mas a democracia necessita dos primeiros. (BOBBIO; 1997,
p.31).

Assim, a cultura vem passando por uma grande crise, que afeta tanto a política quanto a sociedade. Pode-se dizer que também há uma descrença na política por parte da sociedade corroborada com ausência de conhecimento, o que acaba por favorecer o governo, visto que um povo sem conhecimento é mais fácil ser dominado. As transformações culturais e políticas devem ser tomadas percebendo-se os riscos do erro e não somente das melhorias, estabelecendo estratégias que possam ser corrigidas no processo da ação, a partir dos imprevistos e das informações que se tem. Embora a forma de atuação dos indivíduos ocorra de forma diferenciada nos processos que envolvam a representação política, é necessária uma maior participação cotidiana dos sujeitos, não só nas discussões dos projetos, mas no acompanhamento dos mesmos, essa participação dos cidadãos está relacionada com o nível de educação para a cidadania que a sociedade possui.

A cultura política, sempre foi um objeto de poder, domínio e continuará sendo. É o grupo social que define como ela será utilizada. A cultura política faz parte da sociedade. Diante dessas questões delicadas é que se percebe ainda existirem 
contradições nas relações entre sociedade e cultura que precisa ser aproximado por meio da educação. Uma vez que se presume que a própria sociedade na sua diversidade com diferentes classes sociais, níveis educacionais, dentre outros, possui uma percepção diferenciada em relação à cultura política, sua importância e a forma com que ela atinge a sociedade.

Frente o poder e dominação da política e cultura com relação à sociedade verifica-se que ainda hoje o voto é tratado como mercadoria, e os discursos políticos estratégicos em sua maioria, não visam o bem da sociedade, apenas objetivam o poder.

Importante observar que conforme o exposto é imprescindível analisar que a cultura política, cidadania e democracia estão longe de serem concretizadas em nosso país, desta forma, acredita-se que o melhor meio de concretização destes, seria através da educação para a cidadania, sendo que com a educação para a cidadania implementada, aí sim, poderíamos falar em propostas de emenda constitucional realizada pelo povo, uma vez que a dominação não estaria presente de forma tão incisiva, e os próprios cidadãos estariam voltados ao bem comum, e o tratamento do voto como mercadoria deixaria de ser tão frequente.

[...] o ausente crescimento da educação para a cidadania, segundo a qual o cidadão investido do poder de eleger os próprios governantes acabaria por escolher os mais sábios, os mais honestos e os mais esclarecidos dentre os seus concidadãos, pode ser considerado como o efeito da ilusão derivada de uma concepção excessivamente benévola do homem como animal político: o homem persegue o próprio interesse tanto no mercado econômico como no político. Mas ninguém pensa hoje em confutar a democracia sustentando, como se vem fazendo há anos, que o voto é uma mercadoria que se cede ao melhor ofertante. (BOBBIO, 1997, p.11).

Nesta conjectura, se observa que com um povo educado para a cidadania, além de melhorar o exercício da cidadania em sua plenitude e abrangência, estará mais participativo nas decisões do Estado, e propondo emendas constitucionais que seja realmente necessária e que realmente possa contribuir para o desenvolvimento do Estado e da Democracia. Atualmente percebe-se ainda, além do voto tratado como mercadoria, pouco interesse e participação do cidadão nas decisões políticas, sendo que em muitas vezes estes acabam sendo influenciados por aqueles que possuem pouco conhecimento da realidade estatal, como a influência midiática, desta forma para que ocorra uma mudança da atual cultura política:

Necessitamos de homens e mulheres que saibam se sentir maiores do que os limites culturais que os cercam e que tenham a coragem de se recusar a aceitar a realidade na qual estão mergulhados, simplesmente como dada e imutável. É 
urgente humanizar o homem. É necessário transcender e romper os limites do que é dado (FOLLMANN, 2003, p.8).

Destaca-se ainda que a Lei não possui esse condão de mudar uma cultura, tendo em vista que:

Transformações culturais tão profundas não podem introduzir-se de uma vez mediante uma reforma e um texto de lei. Devem ser lançadas através de iniciativas e inovações em princípio limitadas. E é possível que hoje, quando se multiplicam fracassos e dificuldades, que elas sejam aceitas mais do que ontem. (TOURAINE, 1977, p. 291).

Neste sentido, não se pode afirmar que com o implemento da PEC 286/2013, geraria a transformação que se espera na cultura política e na sociedade, sendo que a melhor forma para que se possa chegar a concretização e ampliação da democracia, como já dito, é através da educação para a cidadania.

Diante disso, é necessário buscar meios para a concretização da educação para a cidadania, envolvendo concepções de ensino entre professor e aluno, havendo a preparação para a sociedade bem como tornar os meios para essa preparação eficaz e possível, por meios compreende-se os métodos de ensino.

[...] um educador pode bem ser um filósofo e deve ter a sua filosofia de educação; mas, trabalhando cientificamente nesse terreno, ele deve estar tão interessado na determinação dos fins de educação, quanto também dos meios de realizá-los. (MANIFESTO 1932, In: MAGALDI; GONDRA, 2003, p. 126)

Indispensável à contribuição de John Dewey para a educação, Dewey acreditava que a prática e teoria se encontravam e esta era extremamente importante no processo de educação, sendo que com essa união de teoria e prática provocaria mudanças, gerando assim crescimento intelectual do aluno. $\mathrm{O}$ autor, ainda criticava o modelo tradicional de educação, se referindo a este como pronto e sem relação com a realidade da sociedade, nas palavras de Dewey $(1971$, p. 6):

[...] Aprender significa adquirir o que já está incorporado aos livros e à mente dos mais velhos. Considera-se ainda o que se ensina como essencialmente estático. Ensina-se um produto acabado, sem maior atenção quanto aos modelos e meios porque assim originariamente assim se fez, nem também quanto as mudanças que seguramente irá sofrer no futuro. Trata-se de produto cultural de sociedades que supunham o futuro em tudo semelhante ao passado e que passa a ser usado como alimento educativo de uma sociedade, em que a regra e não a exceção é mudar.

Desta forma, para Dewey a educação deveria estar voltada para a experiência pessoal do aluno bem como a troca de experiências, sendo que a troca de experiências ocorreria num ambiente democrático, sendo que através disso se pode chegar a conclusões em que beneficie toda uma sociedade, uma vez que está também era a 
preocupação de John Dewey, fazer com que a educação fosse fonte de transformação, desta forma, "o maior perigo que ameaça o trabalho escolar é a ausência de condições que tornem possíveis a impregnação de espírito social” (DEWEY, 1959, p. 393).

Conforme o analisado até o momento, com relação à atual cultura política bem como com relação a algumas concepções de educação, conclui-se que na educação para a cidadania o cidadão deve ter conhecimento do porque vota e para quem vota, sem nenhum tipo de dominação, exercendo seus direitos cívicos com liberdade, bem como analisando o bem social. Nesta perspectiva, ao analisar a proposta de emenda constitucional realizada cidadão, percebe-se que os cidadãos também devem ter a mesma consciência, observando as seguintes perguntas: qual a finalidade da emenda? Por que propor a emenda constitucional? Qual o impacto social desta? No entanto, para que o cidadão possa realizar esses questionamentos de modo coerente é imprescindível a educação para a cidadania.

Portanto, pode-se dizer que a educação para a cidadania se propõe a analisar/estudar a realidade do indivíduo, educando-o para um exercício moral e cívico, ou seja, exercer seus direitos civis com liberdade e consciência bem como ter a capacidade de avaliar o bem comum, pensando no social.

\subsection{Democratizando o Poder: Perspectivas sobre um Poder Político Democrático e para a sustentabilidade}

Como já analisado, fica evidente que está longe de se alcançar o ideal de democracia, como já mencionado Rousseau afirmava que a democracia jamais poderia ser alcançada, se isso é verdade ou não, nos resta somente aguardar os caminhos a serem percorridos pela democracia, para obter uma resposta. Todavia, este tópico se preocupa em mesmo com esse futuro democrático incerto, estabelecer alguns rumos pensando num processo de democratização do poder, acreditando que é a partir daí que poderá se alcançar a verdadeira democracia.

Segundo Bobbio (2002, p.77), o que distingue os sistemas democráticos dos não-democráticos são as regras do jogo, ou seja, os inúmeros procedimentos adotados no sistema democrático que tenta legitimar o cidadão como detentor do poder político, a democracia só ocorreria se realmente todos os cidadãos fossem legítimos para exercer o poder político. Deste modo, a democracia só se desenvolveria quando constatado o aumento do número de participantes na tomada de decisões políticas, aí está à raiz do processo de democratização. E mais, ao se falar em democratização do poder político, o 
que deveria ocorrer de fato, era mais do que uma democracia política, e sim, a passagem desta para uma democracia social.

Para tentar estabelecer um conceito mínimo de democracia, à priori, conforme leciona Bobbio (1998, p. 326), com o passar do tempo a democracia foi sendo entendida como sendo um conjunto de regras e de procedimentos para a constituição de um Governo e para a formação das decisões políticas. Dentre estes procedimentos, pode-se mencionar as eleições realizadas pelo povo, sendo que estes, quando atingida a idade deverão ser todos eleitores e seus votos devem ser igualitários, as escolhas realizadas pelo eleitor na democracia, devem ainda, serem realizadas da maneira mais livre possível, sem a imposição de opiniões diversas sendo que para ocorrer a "escolha", deve haver também opções, e por fim, o poder da maioria jamais poderá limitar os direitos da minoria.

É a partir deste procedimento mencionado por Bobbio, que no Estado democrático os representantes chegam ao poder. Há então, uma série de regras para tentar se alcançar a democracia, e consequentemente um poder democrático. $\mathrm{O}$ ideal de poder democrático seria a ideia de que os legitimados a escolher o representante do povo, simplesmente não transfiram o poder que pertence a ele para o representante, de modo a permanecer subordinado ao representante detentor do poder. Deste modo, há o que se falar em poder democrático? Ainda de acordo com Bobbio

\footnotetext{
[...] nenhum regime histórico jamais observou inteiramente o ditado de todas estas regras; e por isso é lícito falar de regimes mais ou menos democráticos. Não é possível estabelecer quantas regras devem ser observadas para que um regime possa dizer-se democrático. Pode afirmar-se somente que um regime que não observa nenhuma não é certamente um regime democrático. (BOBBIO, 1998, p. 327)
}

Assim como a maior parte dos estudiosos da ciência política, Bobbio não acredita que haja um Estado Democrático, no máximo, um Estado mais ou menos democrático, quando obedecida certas regras impostas para a constituição deste regime. Deste modo, também se está longe de alcançar o Poder Democrático. Verifica-se que a democracia, e o poder democrático tomam rumos incertos, quais não se podem prever os resultados, sendo que em todo o caso, tanto as consequências como as melhoras dependem do que fazemos.

Nesta conjectura, Dahal (2001, p.49-50) estabelece critérios para um processo democrático, sendo que um Estado só seria democrático depois de obedecidos esses critérios. Ao elenca-los verifica a presença de uma participação efetiva, onde todos 
deveriam ter igualdade de oportunidades e opiniões, e cada membro deveria ter oportunidades de apreender sobre políticas alternativas e suas consequências, e ainda de poder decidir sobre questões de planejamento, e por fim, menciona a inclusão dos adultos.

Com relação a Democracia no poder político Moreira Neto analisa, através de um viés principiológico, no qual a tendência de uma universalidade da Democracia. A Democracia seria observada como um princípio juspolítico do poder (MOREIRA NETO, 1992, p. 261). O sentido trazido de juspolítico, é que em face à universalidade do poder, é de essencial importância sua compreensão para a política e para o direito, pois é através desse elemento que também se verifica a presença da Democracia.

Assim, cabe ainda ressaltar as indagações realizadas por Bobbio

\begin{abstract}
Mas será possível, num sistema como o sistema democrático, que é tão compacto e coerente do ponto de vista dos procedimentos por ele criados e que estão verificados pela experiência e cristalizados há séculos, distinguir com tanta segurança as regras a serem mantidas e as que devem ser descartadas? Conservaremos o sufrágio universal mas não a liberdade de opinião?, a liberdade de opinião mas não a pluralidade dos partidos?, a pluralidade dos partidos mas não a proteção jurídica dos direitos civis? Em suma, afirmar que nem todas as regras do jogo serão suprimidas é um modo de subtrair-se à obrigação de precisar o próprio ponto de vista a respeito de um problema tão central como é exatamente este das regras do jogo, e sobretudo um indício da absoluta ausência de idéias acerca de sua resolução. (BOBBIO, 2002, p.78-79).
\end{abstract}

Neste aspecto, o autor deixou claro todos os pontos problemáticos decorrentes da democracia e consequentemente do poder político, tenta se efetivar a democracia através de regras, as chamadas regras do jogo, contudo os problemas que cercam esse sistema são muitos e demasiadamente complexos, tornando difícil até mesmo pensar em uma solução para tantos conflitos.

Entretanto, através de tantos empasses que rondam os sistemas democráticos e o exercício do poder político, cabe tão somente, ter em mente como uma possível solução algumas modificações necessárias a essas regras do jogo, contudo, tal mudança deve exigir ainda longos anos de estudos e analises de modo a fazer com que mais do que um princípio ou uma regra prevista na Constituição que a Democracia seja realmente efetivada, bem como a legitimação do povo para o exercício do poder político, todavia, não basta apenas a efetivação da legitimidade do povo, deve haver a legitimação do povo corroborada com o conhecimento político destes. 


\section{CONSIDERAÇÕES FINAIS}

De acordo com o estudo apresentado, pode-se concluir que o Poder trata-se de uma ordem que uma pessoa ou um grupo exerce sobre os demais. $\mathrm{O}$ grande precursor do poder foi Weber e a partir dele que se iniciaram os estudos sobre poder político, Weber então estabelecia uma relação de mando e obediência. Parson e outros pensadores, já estabeleciam a relação de Poder como sendo um meio de legitimar a violência. Percebe-se então que o poder político é o exercício do poder de um homem sobre o outro, como a relação entre governantes e governados.

Considerando que o Poder Político é exercido através da força, errôneo seria dizer que é exercida somente através da força física, pois o que se constata, são diversos meios de exercício dessa força, como a ideologia e dominação. Tendo em vista que o poder implica uma ordem e obediência, revelando assim a tradução do que Weber chama de Herrschaft, ou seja, domínio. A ideologia seria uma forma de legitimação da força, e a ideologia é observada através de discursos direcionados a uma certa classe de pessoas, objetivando a dominação daquele grupo, devido esse objetivo, os discursos seriam diversificados, de modo a atingir o público que lhe convenie naquela dada situação.

Nos Estados Democráticos contemporâneos pode perceber, que a forma de exercício do poder decorre da própria lei e pertence ao Estado, ocorre assim, a conformidade de uma subordinação pelos verdadeiros legitimados ao exercício do poder: o povo. Em face disto, enquanto essa cultura política de dominação permanecer, o (i)legítimo é quem continuará exercendo o poder conforme suas vontades.

Os legitimados ao exercício do Poder no Estado Democrático são os cidadãos, contudo, diz- se que essa legitimidade é meramente formal, pois apenas escolhe o representante, esse processo de escolha se dá através da eleição, sendo adotado um sistema majoritário, onde a decisão da maioria se sobrepõe sobre da minoria. Percebe-se então que a Democracia nada mais é do que o governo exercido pelos representantes da maioria, onde a minoria é a parte mais fraca, e possui o dever de se subordinar as imposições e forma de governo da maioria.

Em suma, é através da persuasão que a maioria se torna uma maioria. Contudo, como já evidenciado, o grande problema está na dominação dos discursos, ocorrendo que na democracia, a dominação toma conta dos legitimados á escolher os representantes do povo, deste modo, acabam assim, exercendo apenas um poder formal, 
se é que se pode chamar de poder. Deste modo, o Estado possui a mais terrível das forças, que não é a física, mas sim, a psíquica, a força da alienação.

A limitação do poder poderia ocorrer através de instrumentos do ordenamento jurídico, instrumentos esses que estão presentes de forma explícita no Estado Democrático de Direito. Por conseguinte, verifica-se que as bases políticas brasileiras, estão longe de serem tão bem estruturadas de modo a vir limita-lo. Dahal apresentou uma proposta quanto ao número de cidadãos legitimados para participar de eleição, que seria como um limite ao poder político, assim, o entende que quanto menor a localidade que habita esses cidadãos, menor é a delegação de poder ao representante.

Portanto o que distingue os sistemas democráticos dos não-democráticos são as regras do jogo, os inúmeros procedimentos adotados no sistema democrático que tenta legitimar o cidadão como detentor do poder político, a democracia só ocorreria se realmente todos os cidadãos fossem legítimos para exercer o poder político. A democracia é entendida como sendo um conjunto de regras e de procedimentos para a constituição de um Governo e para a formação das decisões políticas é através desse procedimento que se tem tentado a chegar a Democracia e o poder democrático. Contudo o poder democrático toma rumos incertos, quais não se podem prever os resultados, sendo que em todo o caso, tanto as consequências como as melhoras dependem das atitudes.

A sustentabilidade poderá ser alcançada quando por meio da democracia despertar-se a percepção e conscientização da sociedade para que ela enquanto ator social seja o agente transformador por meio de suas ações. Instrumentos legais existem, mas ainda falta muita participação política e conhecimento das formas de atuação para a mudança social.

\title{
REFERÊNCIAS
}

AZAMBUJA, Darcy. Introdução à ciência política. 2. ed. São Paulo: Globo, 2008.

\author{
ABRAMOVICH, V.; COURTIS, C. Los derechos sociales como derechos \\ exigibles.
}

2. ed. Madrid: Editoria Trota, 2004.

BEDIN, Gilmar Antonio. Os direitos do homem e o neoliberalismo. 3. ed. Ijuí:UNIJUÍ, 2002. 
BOBBIO, Norberto. O futuro da Democracia. 8. ed. São Paulo: Paz e Terra, 2002. Teoria Geral da Política: a filosofia política e as lições dos clássicos. Rio de Janeiro: Campus/Elsevier, 2000.

BAKUNIN, Mikhail. A ilusão do sufrágio universal. Disponível em: <http://www.espacoacademico.com.br/016/16bakunin.htm>. Acesso em: 16 out 2014.

BONAVIDES, Paulo. Curso de Direito Constitucional. 13. ed. rev. atual. São Paulo: Malheiros Editores, 2003.

CANOTILHO, José Joaquim Gomes. Direito constitucional e teoria da Constituição. 5. ed. Coimbra: Almedina, 2003.

COSTA, Nelson Nery. Ciência Política. 3. ed. Rio de Janeiro: Forense, 2012.

DAHAL, Robert A. Sobre a Democracia. Brasília: Editora Universidade de Brasília, 2001. DUCH, Lluís. Mito, interpretación y cultura. Tradução Francesca Babí i Poça. Barcelona: Herder. 1998.

FERREIRA, Luis Alexandre Cruz; TÁRREGA, Maria Cristina Vidotte Blanco. Reforma do Poder Judiciário e direitos humanos. In:__. Reforma do Judiciário: Primeiras reflexões sobre a Emenda Constitucional n. 45/2004. São Paulo: Revista dos Tribunais, 2005. 447-466.

FIORILLO, Celso Antônio Pacheco e RODRIGUES, Marcelo Abelha. Manual de direito ambiental e legislação aplicável. São Paulo: Max Limonad, 2003.

GERARD, Lebrun. O que é o Poder. Brasiliense, 1981.

HABERMAS, Jürgen. Direito e Democracia: Entre facticidade e validade. Vol. II. Rio de Janeiro: Tempo Brasileiro, 1997.HÄBERLE, Peter. Direitos Fundamentais. 2003. MAZZUOLI, Valério de Oliveira. Direitos humanos \& relações internacionais. São Paulo: Agá Júris, 2000.

MEZZAROBA,Orides; MONTEIRO, Claúdia Servilha. Manual de metodologia da pesquisa no direito. São Paulo: Saraiva, 2004.

MORAIS, José Luiz Bolzan de. As crises do estado e da constituição e a transformação espacial dos direitos humanos. Porto Alegre: Livraria do Advogado, 2002.

MORIN, Edgar. Terra Pátria. 2. ed. Lisboa: Instituto Piaget, 2001.

MOREIRA NETO, Diogo de Figueiredo. Teoria do poder: sistema de direito político. São Paulo: RT, 1992.

MUKAI, Toshio. Direito ambiental sistematizado. 4. ed. São Paulo: Forense Universitária, 2004. 
NUNES, Luiz Antonio. A Lei, O Poder e os Regimes Democráticos. São Paulo: Editora Revista dos Tribunais, 1991.

PAUL, Kelly... [et al]. O Livro da Política. São Paulo: Globo, 2013.

POUlAnTZAS, Nicos. O Estado, O Poder, O Socialismo. 4 ed. São Paulo: Graal, 2000.

PIOVESAN, Flávia. Direitos Humanos e o Direito Constitucional Internacional. 7. ed. rev., ampl. e atual. São Paulo: Saraiva, 2006

SANTOS, Boaventura de Sousa. Democratizar a democracia: os caminhos da democracia participativa. Rio de Janeiro:Civilização Brasileira, 2002.

SARLET, Ingo Wolfgang. A eficácia dos direitos fundamentais. Porto Alegre: Livraria do Advogado,

2004.

SILVA, José Afonso da. Curso de direito constitucional positivo. 22. ed. São Paulo: Malheiros, 2004.

SINGER, Peter. Liberación Animal. 2. ed. Madrid: Editorial Trotta, 1999.SEN, Amartya. Desenvolvimento como liberdade. Tradução Laura Teixeira Motta. São Paulo: Companhia das Letras, 2000.

ZIMMERMANN, Augusto. Curso de direito constitucional. 2 ed. Rio de Janeiro: Lumen Juris, 2002. 